\title{
Estudo do Efeito do Ozônio Gerado Durante Ensaios Elétricos em Equipamentos de Segurança Confeccionados em Borracha Natural
}

\author{
Caroline I. Lisevski, Camila M. 0. Wolski, Marilda Munaro \\ Departamento de Materiais, LACTEC \\ Rafael G. Serta, Rafael P. Machado, Edemir Kowalski \\ Departamento de Meio Ambiente, LACTEC \\ Anselmo Pombeiro \\ Departamento de Manutenção de Substações, COPEL
}

Resumo: A borracha natural é muito empregada na confecção de equipamentos de proteção individual e coletiva para o setor elétrico devido à sua excelente flexibilidade e isolamento elétrico. Para garantir a segurança dos eletricistas, os equipamentos são testados periodicamente, por ensaios elétricos. Durante esses ensaios ocorrem descargas corona que ionizam o ar, gerando ozônio, que pode reagir com a borracha natural mudando suas características iniciais. Neste trabalho são apresentadas as alterações provocadas pela exposição ao ozônio, em concentração medida durante os ensaios elétricos, nos equipamentos confeccionados em borracha natural. As amostras foram testadas com e sem tensão mecânica e avaliadas por microscopia e ensaios mecânicos. Foi observada alteração superficial nas amostras sem tensão mecânica, para as amostras tensionadas houve aparecimento de fissuras macroscópicas e decréscimo na resistência mecânica.

Palavras-chave: Borracha natural, ozônio, degradação, propriedades mecânicas.

\section{The Behavior of Natural Rubber Used in Line-Life Equipment Submitted to Ozone Concentration Observed During the Electrical Test}

\begin{abstract}
Natural rubber is used to manufacture line-life equipment due to its insulating and flexibility characteristics. In order to provide safety to lineman, these pieces of equipment are periodically submitted to electrical maintenance tests. During these tests, corona discharges occur generating ozone gas which can react with natural rubber, thus ageing it and affecting its initial characteristics. This study shows changes caused by ozone exposure with concentrations prevailing during electrical tests in equipment made of natural rubber. The samples were tested with and without mechanical deformation and evaluated by microscopy and mechanical properties. Superficial changes were observed in samples which were not exposed to mechanical stress, while for mechanically stressed samples there were macroscopic cracks and decrease in the mechanical properties.
\end{abstract}

Keywords: Natural rubber, ozone, degradation, mechanical properties.

Introdução

A estrutura química da borracha natural lhe confere propriedades como excelente flexibilidade, elasticidade, resistência à tração ${ }^{[1]} \mathrm{e}$ isolamento elétrico ${ }^{[2]}$, o que faz com que esta seja amplamente empregada no setor elétrico ${ }^{[3]}$. Neste setor, a borracha natural é utilizada na fabricação de ferramentas para manutenção de linha viva como luvas, mangas e lençóis isolantes ${ }^{[2,4]}$.

Os equipamentos utilizados na manutenção de redes energizadas necessitam estar em perfeitas condições de uso e para isso são realizadas inspeções visuais e ensaios elétricos, regulamentados por normas nacionais e internacionais ${ }^{[2,5]}$. As inspeções visuais são realizadas com o objetivo de verificar se o material não apresenta fissuras, rasgos, mudança de coloração entre outros, enquanto os testes elétricos visam identificar se a ferramenta possui a característica de isolamento elétrico. Durante os testes elétricos, devido às descargas elétricas de corrente alternada (AC), o ar é ionizado por descarga corona ${ }^{[6]}$, produzindo ozônio $^{[7]}$. Como a borracha natural apresenta baixa resistência ao ozônio, ocorre o aparecimento de fissuras alterando as propriedades do material ${ }^{[8,9]}$, reduzindo a vida útil das ferramentas.

$\mathrm{O}$ ozônio $\left(\mathrm{O}_{3}\right)$ reage com as duplas ligações da molécula de borracha natural, causando quebra e/ou rearranjo das cadeias poliméricas $^{[8,10]}$, o que pode diminuir a resistência mecânica e o isolamento elétrico, comprometendo a segurança dos técnicos durante a manutenção das redes elétricas.

Muitas investigações foram realizadas acerca das propriedades da borracha natural sob ação do ozônio, no entanto, as concentrações utilizadas na literatura são baixas (0,5 a 2 ppm) ${ }^{[8-14]}$ quando comparadas às concentrações encontradas nos ensaios periódicos de manutenção das ferramentas de linha viva (8 a $32 \mathrm{ppm})$.

Neste trabalho será apresentado o estudo realizado em três equipamentos de manutenção de linha viva confeccionados em borracha natural, submetidos à concentração de $30 \mathrm{ppm}$ de $\mathrm{O}_{3}$, procurando simular a solicitação imposta durante os ensaios elétricos periódicos de inspeção.

\section{Experimental}

Materiais

Foram analisados três equipamentos comerciais para proteção individual e coletiva, confeccionados em borracha natural,

Autor para correspondência: Marilda Munaro, Instituto de Tecnologia Para o Desenvolvimento, Universidade Federal do Paraná - UFPR,

Jardim das Américas, CP 19067, CEP 81531-980, Curitiba, PR, Brasil, e-mail: marilda@lactec.org.br 
usados durante a manutenção de linhas elétricas energizadas. Os equipamentos lençol, luva e manga isolantes foram fornecidos por fabricantes diferentes e denominados respectivamente de A, B e C, e apresentaram as características descritas na Tabela 1.

\section{Geração de ozônio e condicionamento das amostras}

O ozônio foi gerado a partir do ar atmosférico, previamente seco pela passagem por sílica, sendo impulsionado para um gerador e introduzido na câmara onde as amostras se encontram. A concentração de $\mathrm{O}_{3}$ no interior da câmara foi controlada por um analisador modelo APOA-360 da marca Horiba, com precisão de 0,001 ppm e a leitura da concentração foi realizada a cada dois segundos.

A concentração de $\mathrm{O}_{3}$ usada no condicionamento das amostras foi de $30 \pm 2$ ppm, determinada com base nas medições feitas durante os ensaios elétricos periódicos. O condicionamento das amostras foi realizado por 30, 90, 120 e 240 minutos para as amostras sem deformação mecânica e por 15, 30, 45 e 90 minutos para as amostras sob $10 \%$ de deformação mecânica.

\section{Microscopia óptica}

Para observar as alterações macroscópicas na superfície das amostras, foi utilizado o microscópio digital da marca Dino-Lite modelo 313T.

\section{Microscopia eletrônica de varredura (MEV)}

Neste ensaio foi utilizado o microscópio eletrônico de varredura Philips, modelo XL30, com detector de energia dispersiva de raio X (EDS) marca EDAX. As amostras foram metalizadas em aparelho de marca BAL-TEC modelo SCD 005.

\section{Tração à ruptura}

O ensaio de tração foi realizado conforme a norma ASTM D 412, em equipamento Instron modelo 4467, com célula de carga de $100 \mathrm{kN}$, na velocidade de $50 \mathrm{~mm} / \mathrm{min}$ e L0 de $20 \mathrm{~mm}$. Os corpos de prova foram obtidos dos equipamentos, no formato de gravatas modelo NBR NM-IEC 60811-1-1.

\section{Resultados e Discussões}

As amostras expostas ao ozônio sem deformação não apresentaram alterações em sua superfície, como mudança de coloração ou presença de fissuras macroscópicas.

Os corpos de prova da amostra A, expostas ao ozônio sob 10\% deformação, apresentaram fissuras em toda a área tracionada, e o tamanho e a profundidade destas fissuras aumentaram com tempo de exposição, conforme pode ser observado na Figura 1. Os corpos de prova expostos por mais de 45 minutos sob esta condição romperam.

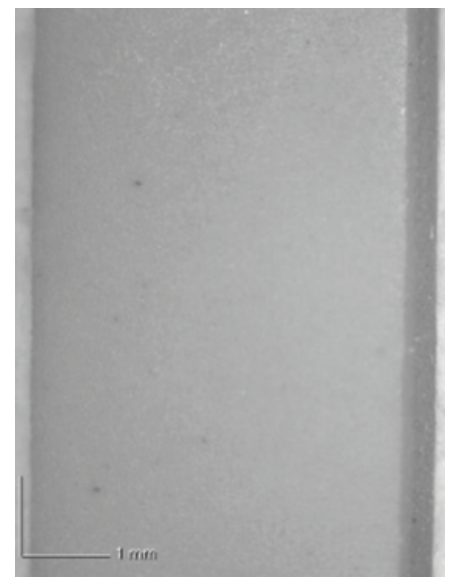

(a)

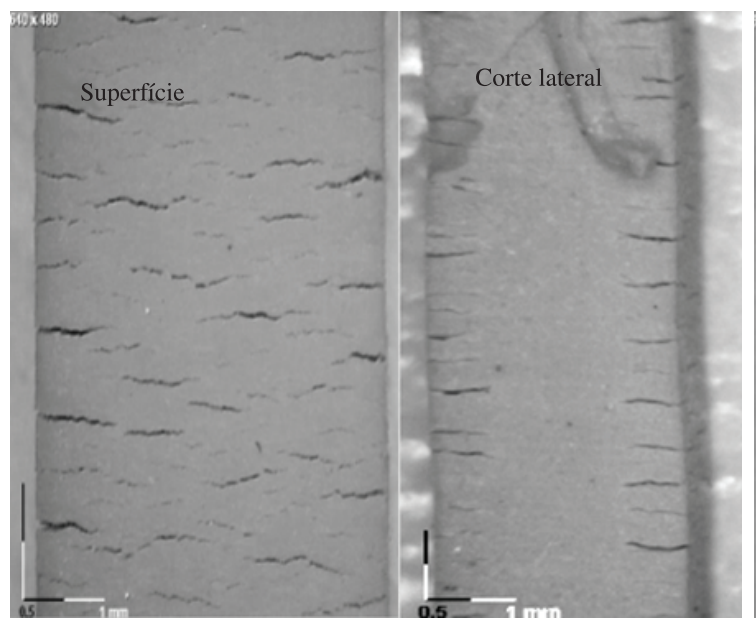

(c)

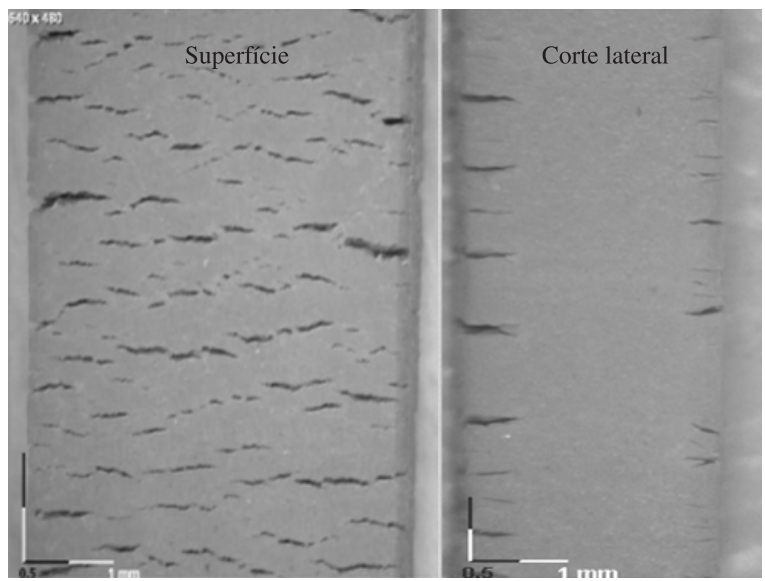

(b)

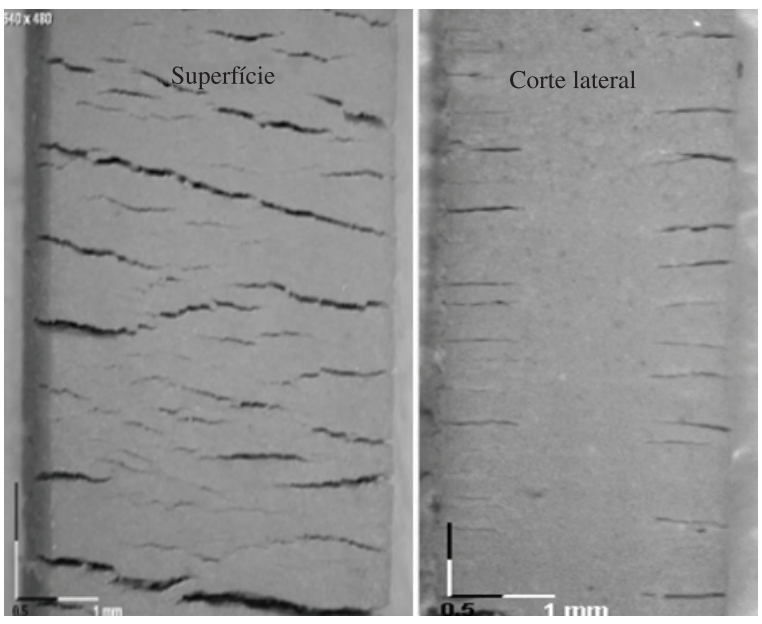

(d)

Figura 1. Imagens obtidas por microscopia óptica da amostra A, sob 10\% de deformação mecânica: a) antes da exposição ao ozônio; b) após 15 minutos; c) após 30 minutos; d) após 45 minutos. 
As imagens para a amostra B, expostas ao ozônio sob $10 \%$ deformação, podem ser observadas na Figura 2, onde notase a presença de fissuras, mas em menor profundidade quando comparadas à amostra A na mesma condição.

Para a amostra C tensionada (Figura 3) as fissuras observadas são menores do que as da amostra $\mathrm{A}$, mas maiores que as da amostra B.

As imagens de MEV foram feitas apenas nos corpos de prova expostos ao ozônio sem tensão mecânica aplicada.

Na Figura 4 estão apresentadas as imagens obtidas da superfície da amostra A. Observa-se que o material exposto ao ozônio apresenta fissuras micrométricas que aumentam em quantidade com o tempo de exposição. Também foi observada a exudação de cristais de enxofre, utilizado no processo de vulcanização. A presença do elemento químico enxofre foi confirmada pela análise de energia dispersiva de raio $\mathrm{X}$ (EDS) (Figura 5a).

Na Figura 6 estão as imagens de MEV obtidas para amostra B. Nota-se que antes da exposição ao ozônio, a amostra apresentou

Tabela 1. Características das amostras de borracha natural estudadas.

\begin{tabular}{cccc}
\hline & $\left.\begin{array}{c}\text { Temperatura de } \\
\text { transição vítrea }\end{array}{ }^{\circ} \mathbf{C}\right)$ & $\begin{array}{c}\text { Teor de material } \\
\text { orgânico }^{\mathbf{b}}(\%)\end{array}$ & $\begin{array}{c}\text { Teor de cargas } \\
\text { inorgânicas }^{\mathbf{b}}(\boldsymbol{\%})\end{array}$ \\
\hline A & -67 & 63,8 & 36,2 \\
B & -66 & 93,1 & 6,9 \\
C & -63 & 88,7 & 11,3 \\
\hline
\end{tabular}

${ }^{\mathrm{a}}$ Obtido por Calorimetria Diferencial de Varredura (DSC). ${ }^{\mathrm{b}}$ Obtido por Análise Termogravimétrica (TGA).

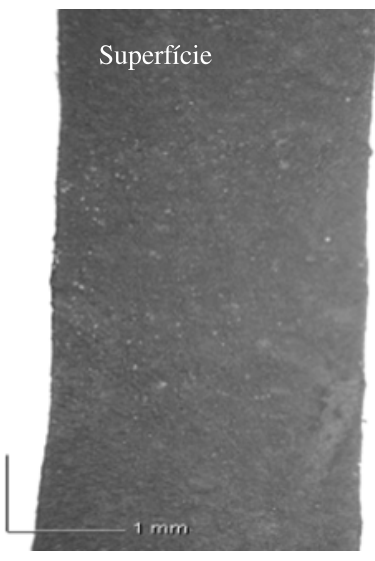

(a)

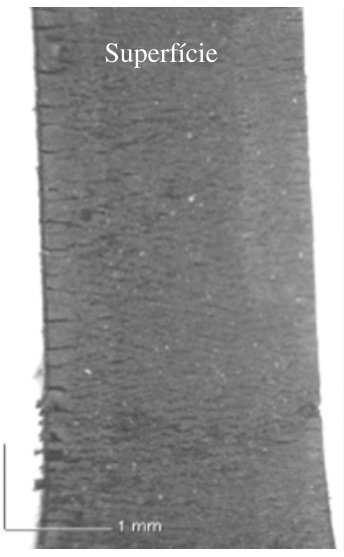

(b)

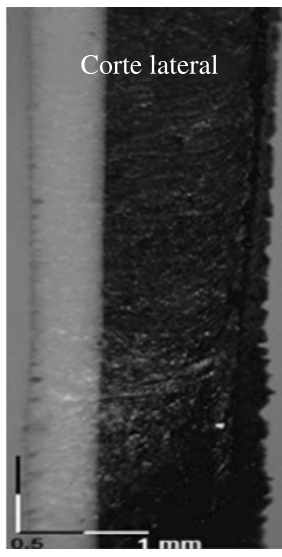

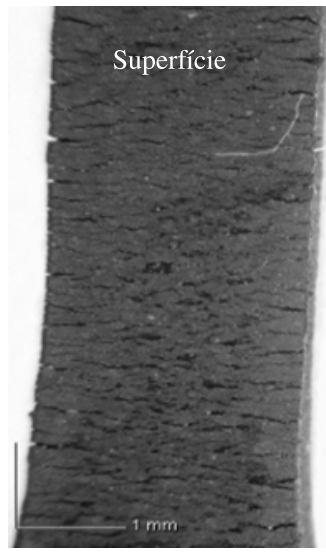

(d) rugosidade e microfissuras, provavelmente causadas devido à halogenação, que é realizada para tornar a luva mais agradável ao toque $^{[2]}$. A halogenação foi confirmada pela presença do elemento cloro na análise de EDS (Figura 5b). O material que foi exposto ao $\mathrm{O}_{3}$ apresentou a remoção da camada halogenada, sendo mais intensa para maior tempo de exposição, e com 240 minutos de exposição nova camada começa a ser removida. A remoção da camada clorada pode ter ocorrido pela maior permeação do ozônio devido a presença das microfissuras e foi confirmada pela redução da intensidade do pico de cloro no espectro obtido por EDS, como pode ser observado pelas Figuras 5b, c.

$\mathrm{Na}$ Figura 7 pode-se observar as imagens da superfície da amostra C exposta ao ozônio sob tensão mecânica, onde observa-se o aparecimento de microfissuras com a exposição ao ozônio, mas em menor incidência que na amostra $\mathrm{A}$.

$\mathrm{Na}$ amostra A não foi encontrado cloro ou outro halogênio e na amostra $C$ foi observada quantidade menor de cloro que na amostra B (Figura 5).

Os resultados obtidos no ensaio de tração à ruptura podem ser observados na Figura 8. Nota-se que, para as amostras A e C expostas à ação do ozônio sem deformação mecânica, as propriedades de alongamento e tensão de ruptura não apresentaram alterações significativas, enquanto que a amostra B apresentou aumento nessas propriedades. Esse fato pode ser justificado pela amostra B apresentar microfissuras antes da exposição ao ozônio, e com a exposição ocorreu a remoção da camada fissurada, como 


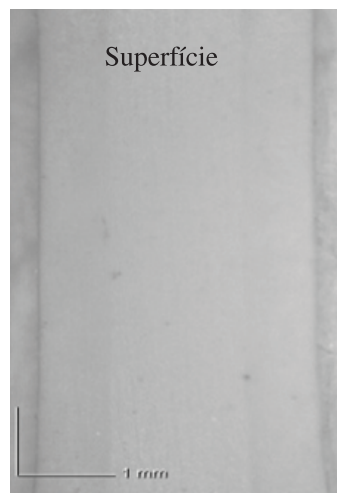

(a)

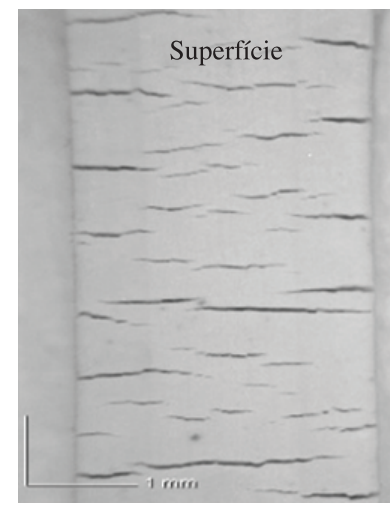

(d)

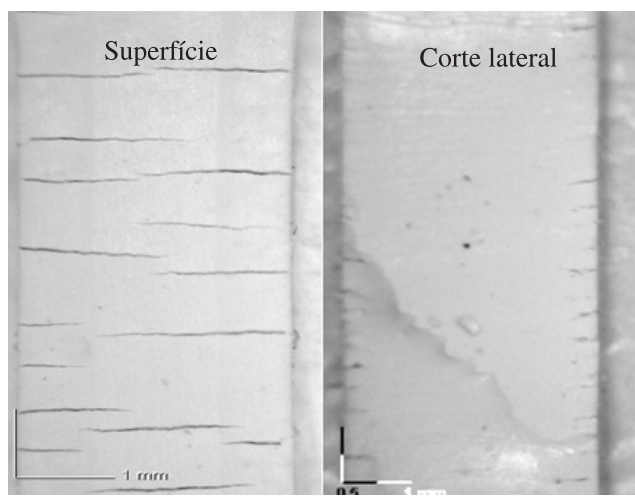

(c) (b)
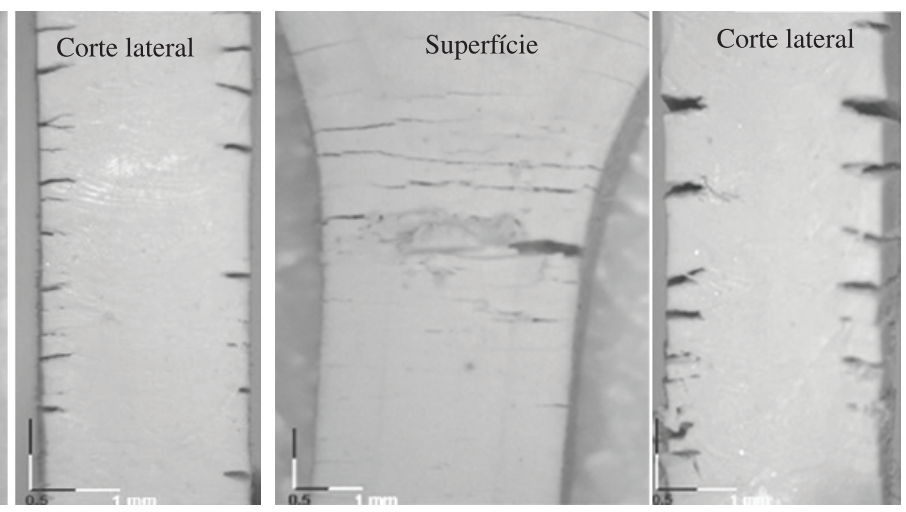

(e)

Figura 3. Imagens obtidas por microscopia óptica da amostra C, sob $10 \%$ de deformação mecânica: a) antes da exposição ao ozônio; b) após 15 minutos; c) após 30 minutos; d) após 45 minutos; e) após 90 minutos.

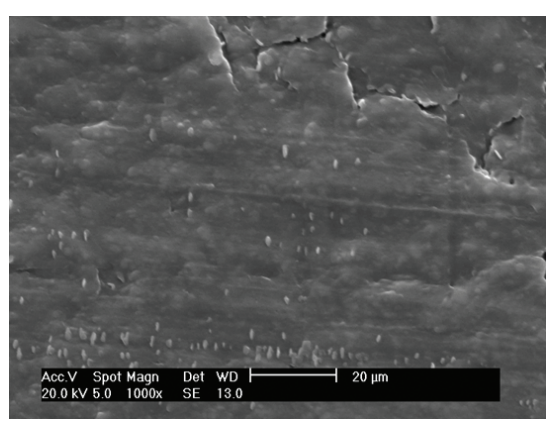

(a)

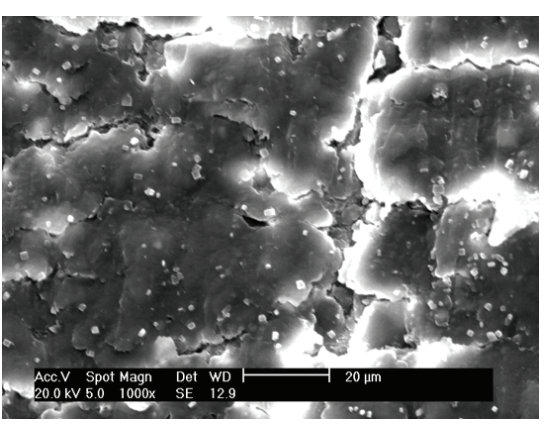

(b)

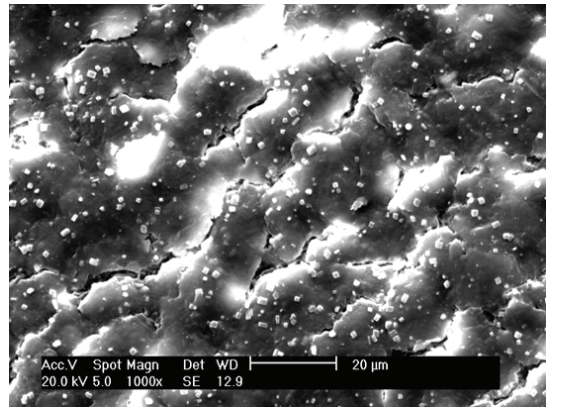

(c)

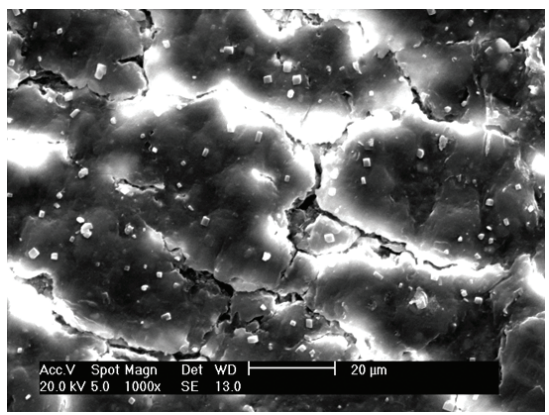

(d)

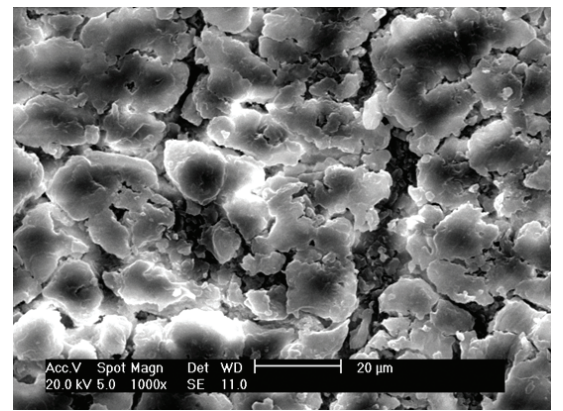

(e)

Figura 4. Imagens de MEV da amostra A: a) antes da exposição ao ozônio; b) após 30 minutos; c) após 90 minutos; d) após 120 minutos; e) após 240 minutos. 

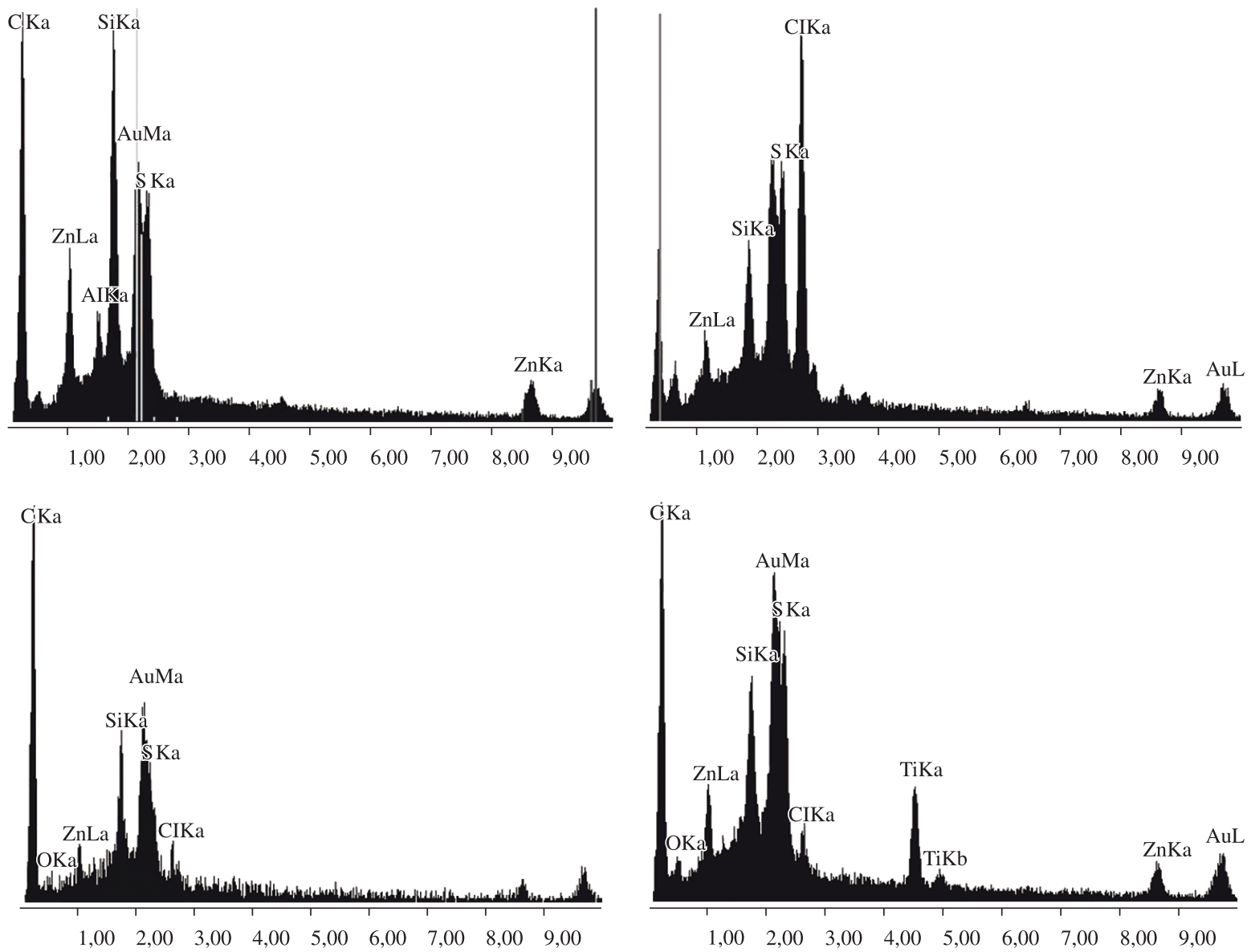

Figura 5. Espectros obtidos por EDS da superfície das amostras: a) amostra A antes da exposição ao ozônio; b) amostra B antes da exposição ao ozônio; c) amostra B após 120 minutos de exposição ao ozônio; d) amostra C antes da exposição ao ozônio.

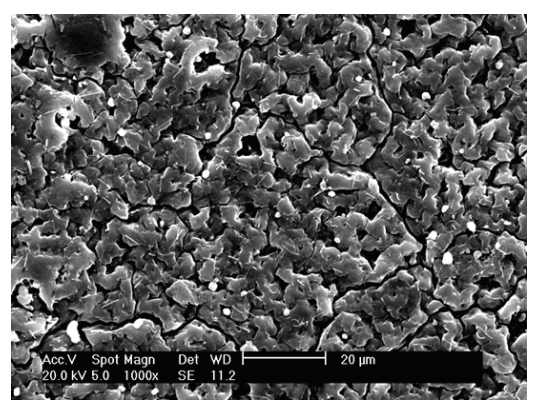

(a)

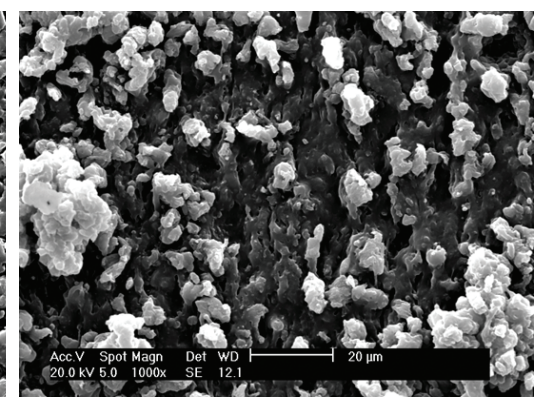

(b)

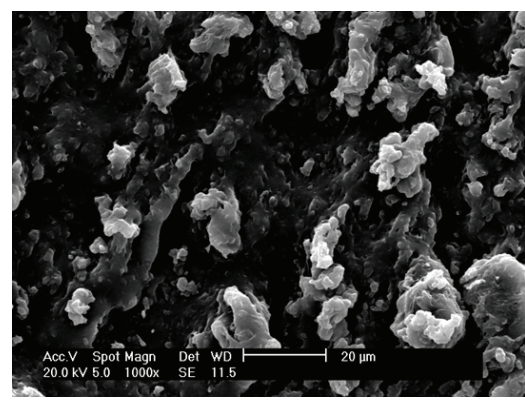

(c)

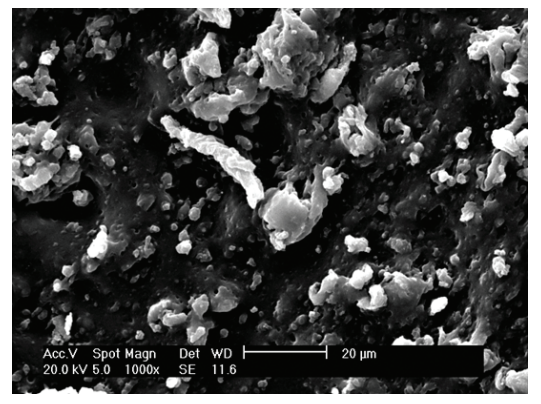

(d)

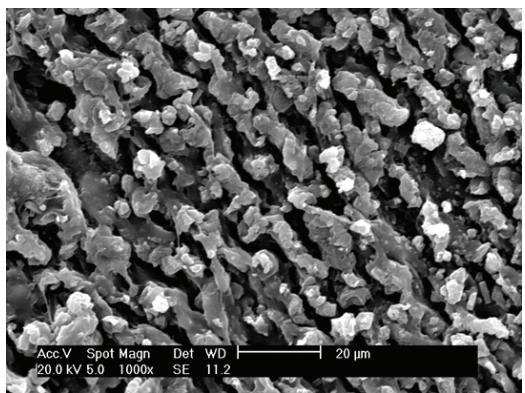

(e)

Figura 6. Imagens de MEV da amostra B: a) antes da exposição ao ozônio; b) após 30 minutos; c) após 90 minutos ; d) após 120 minutos; e) após 240 minutos. 


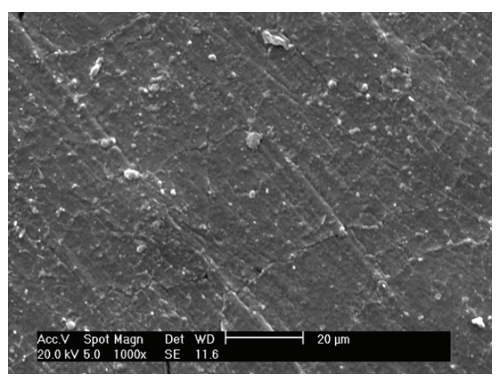

(a)

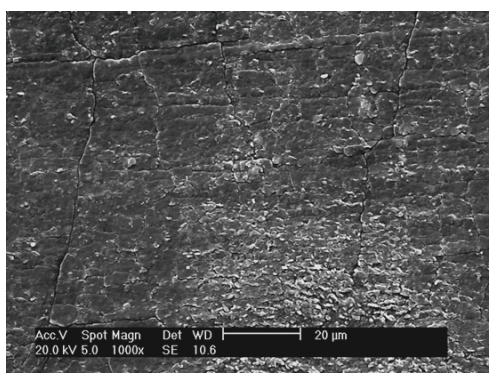

(b)

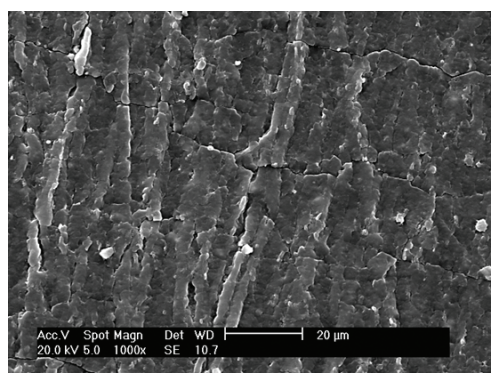

(c)

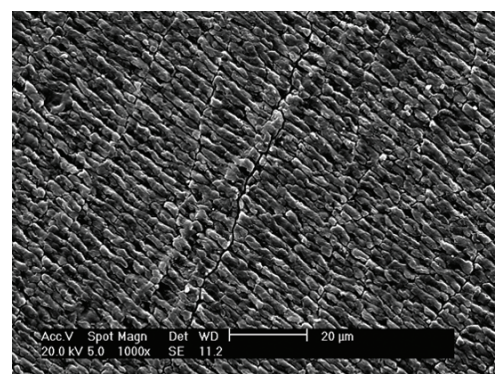

(d)

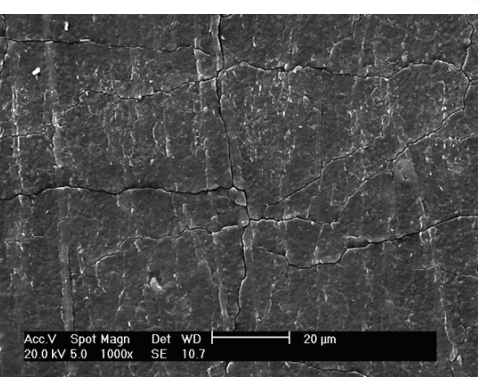

(e)

Figura 7. Imagens de MEV da amostra C: a) antes da exposição ao ozônio; b) após 30 minutos; c) após 90 minutos; d) após 120 minutos; e) após 240 minutos.

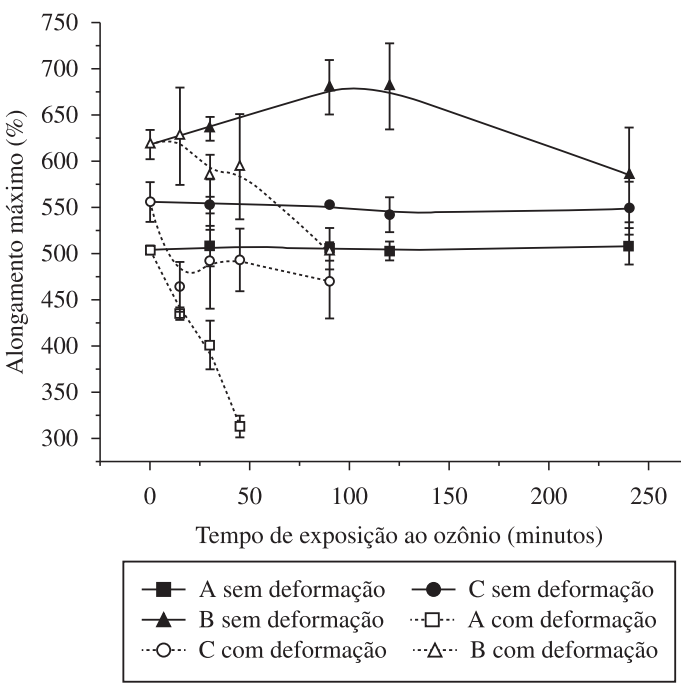

(a)

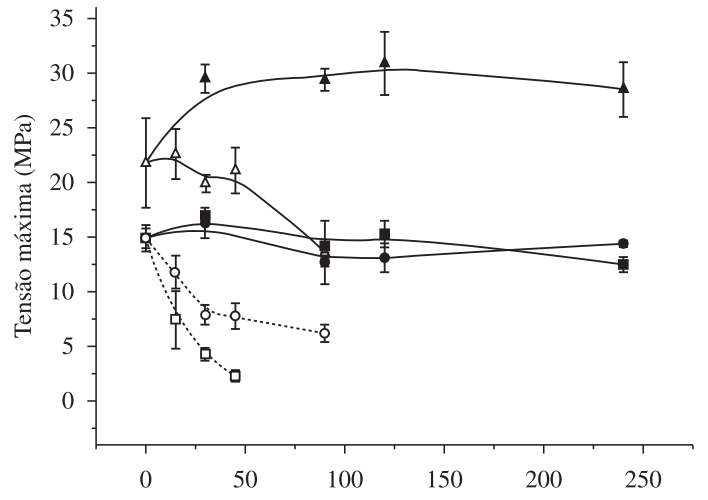

Tempo de exposição ao ozônio (minutos)

(b)

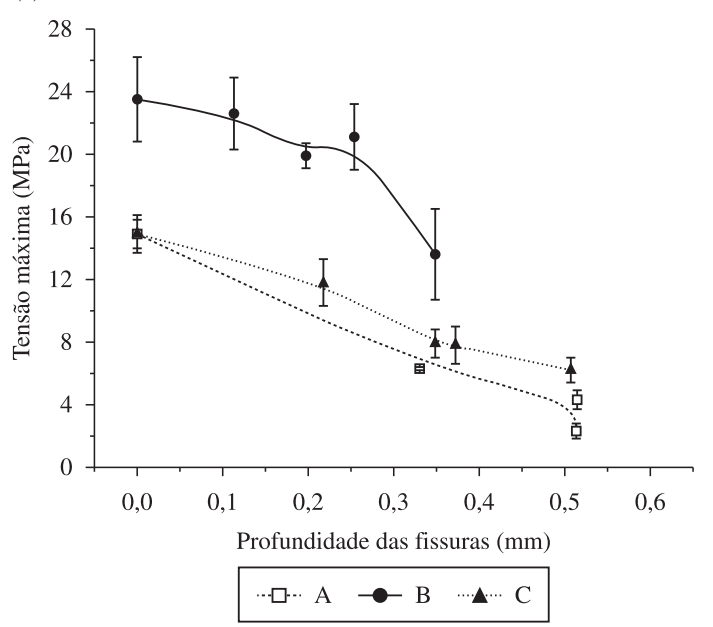

(c)

Figura 8. Variação da propriedade mecânica em função do tempo de exposição, para as amostras expostas ao ozônio sem deformação mecânica e sob $10 \%$ de deformação: a) alongamento máximo; b) tensão máxima; c) variação da tensão máxima em função da profundidade das fissuras. 
foi observada pela análise de microscopia eletrônica de varredura, aumentando a resistência mecânica.

As amostras A e C condicionadas sob deformação mecânica apresentaram redução nas propriedades mecânicas, mesmo para pequenos intervalos de tempo de exposição. Para a amostra B observa-se maior variação para exposições acima de 45 minutos. Esse fato está diretamente relacionado com a profundidade da fissura como pode ser observado na Figura 8c.

Com os resultados obtidos foi possível constatar que as amostras sem tensão mecânica aplicada não apresentaram alterações significativas nas propriedades mecânicas, possivelmente porque a difusão do ozônio para o interior da amostra é pequena ${ }^{[15]}$, mostrando que mesmo na concentração de ozônio utilizada neste trabalho, a degradação foi superficial. Quando a amostra está tensionada, a difusão do ozônio aumenta, provocando rápido aparecimento de fissuras macroscópicas e variação nas propriedades mecânicas.

Segundo a literatura, a variação na permeabilidade pode ser ocasionada pelo método de vulcanização das borrachas, onde há maior permeação de gases em compostos vulcanizados por enxofre quando comparados com os vulcanizados com peróxido, e/ou pela compatibilidade da carga com a matriz polimérica ${ }^{[16]}$. Esses fatos podem justificar a menor resistência ao ozônio da amostra A que apresentou migração de cristais de enxofre e maior concentração de teor de carga inorgânica.

Em baixas concentrações de ozônio, como encontrado na literatura $^{[8-14]}$, os efeitos do ozônio sobre a borracha natural demoram horas e até dias para serem observados, enquanto que na concentração utilizada neste trabalho em poucos minutos foram observadas alterações significativas.

\section{Conclusões}

As amostras condicionadas em ozônio sem deformação mecânica, nas concentrações geradas durante os ensaios elétricos, apresentaram apenas microfissuras que não alteraram significativamente as propriedades mecânicas. As amostras expostas sob deformação mecânica apresentaram rápido aparecimento de fissuras e redução nas propriedades mecânicas.

Com os resultados fica comprovado que os equipamentos em borracha natural, usados na manutenção de linhas energizadas, são degradados durante os ensaios periódicos por estarem submetidos a altas concentrações de ozônio e tensão mecânica.

\section{Agradecimentos}

Os autores gostariam de agradecer a COPEL, LACTEC e UFPR pela parceria no desenvolvimento desse projeto de pesquisa, a ANEEL e o CNPq pelo suporte financeiro.

\section{Referências Bibliográficas}

1. Somers, A. E. et al - Polym. Degrad. Stabil., 70, p.31(2000). http:// dx.doi.org/10.1016/S0141-3910(00)00076-8

2. Companhia Paranaense de Energia - COPEL. - "Manual de Instruções Técnicas COPEL", COPEL (2006).

3. Santos, M. A.; Mattoso, L. H. C.; Defácio, R. \& Avlyanov, J. Polímeros, 11, p.126 (2001).

4. Paz Junior, E. M.; Wolski, C. M. O.; Machado, R. P.; Kowalski, E. \& Munaro, M. - Polímeros, 20, p.236 (2010).

5. International Electrotechnical Commission - IEC. - "IEC 60903: Live Working - Gloves of Insulating Material”, IEC (2002).

6. Kreuger, F. H. - "Partial Discharge Detection in High-Voltage Equipment", Butterworths (1986).

7. Kolcio, N. - IEEE T. Power Ap. Syst., PAS-102, p.102 (1983). http:// dx.doi.org/10.1109/TPAS.1983.318163

8. Radakrishnan, C. K.; Alex, R. \& Unnikrishnan, G. - Polym. Degrad. Stabil., 91, p.902 (2006).

9. Rodrigues, F. H. A. et al. - Polym. Int., 53, p.733 (2004). http://dx.doi. org/10.1002/pi.1265

10. Escócio, V. A.; Martins, A. F.; Visconte, L. L. Y. \& Nunes, R. C. R. Polímeros, 14, p.13 (2004).

11. Ivan, G. \& Giurginca, M. - Polym. Degrad. Stabil., 62, p.441(1998). http://dx.doi.org/10.1016/S0141-3910(97)00127-4

12. Cataldo, F. - Polym. Degrad. Stabil., 73, p.511 (2001). http://dx.doi. org/10.1016/S0141-3910(01)00140-9

13. Tse, M. F. - J. Appl. Polym. Sci., 103, p.2183 (2006). http://dx.doi. org/10.1002/app.25139

14. Findik, F.; Yilmaz, R. \& Köksal, T. - Mater. Design, 25, p.269 (2004). http://dx.doi.org/10.1016/j.matdes.2003.11.003

15. Andrews, E. H. \& Braden, M. J. Appl. Polym. Sci., 55, p.787 (1961).

16. George, S. C.; Thomas S. - Prog. Polym. Sci., 26, p.985 (2001). http:// dx.doi.org/10.1016/S0079-6700(00)00036-8

Enviado: 02/03/11

Reenviado: 15/07/11

Aceito: 19/07/11 